\title{
THE ADSORPTION OF $\mathrm{O}_{2}$ ON ZnO AND THE LOGARITHMIC LAW
}

\author{
Veronica BRĂTAN and Niculae I. IONESCU* \\ "Ilie Murgulescu" Institute of Physical Chemistry of the Roumanian Academy, 202 Spl. Independenței, \\ 060021 - Bucharest, Roumania, Phone/Fax (40-21) 3121147
}

$$
\frac{\mathrm{dq}}{\mathrm{dt}}=\mathrm{a} \exp \left(-\mathrm{bq}^{2}\right)
$$

\section{INTRODUCTION}

The formal kinetics of gas adsorption on solid surfaces is usually determined by the logarithmic rate law used either in its differential form:

$$
\frac{\mathrm{dq}}{\mathrm{dt}}=\mathrm{a} \cdot \exp (-\mathrm{bq})
$$

or in its integral one:

$$
\mathrm{q}=\frac{1}{\mathrm{~b}} \cdot\left[\ln \left(\mathrm{t}+\mathrm{t}_{0}\right)-\ln \mathrm{t}_{0}\right]
$$

where $q$ is the adsorbed gas quantity at the $t$ moment, $\mathrm{a}, \mathrm{b}$ are constants and $\mathrm{t}_{0}=\frac{1}{\mathrm{ab}}$ if $\mathrm{t}=0, \mathrm{q}=0$.

But the differential form of the logarithmic law can be represented also by another form, obtained from equation (1), namely:

$$
\frac{\mathrm{dq}}{\mathrm{dt}}=\frac{1}{\mathrm{~b}} \cdot \frac{1}{\mathrm{t}+\mathrm{t}_{0}}
$$

In this case, the initial conditions $\mathrm{t}=0, \mathrm{q}=0$ cannot be applied because equation (3) becomes:

$$
0=\frac{1}{\mathrm{~b}} \cdot \frac{1}{\mathrm{t}_{0}}
$$

which is not true. The equation (3) is valid only if $\mathrm{t}=0, \mathrm{q} \neq 0$ and $\mathrm{b}$ is a constant.

\footnotetext{
${ }^{*}$ Corresponding author: ionescu@icf.ro
}

All the equations forms (1)-(3) have been intensively studied ${ }^{1-6}$ and three classes of models for the explanation of this law, based on: active sites number variation, variable activation energy or non-uniform surface sites, have been developed. $^{7}$

The adsorption of oxygen of an n-type oxide surfaces, like $\mathrm{ZnO}$, was studied using also the logarithmic law and several kinetic models have been proposed. ${ }^{8-17}$

In this paper we intend to analyze if there are cases in which the adsorption of oxygen on $\mathrm{ZnO}$ cannot be described by these logarithmic rate law.

\section{THE MODEL}

Let the adsorption of $\mathrm{O}_{2}$ on a $\mathrm{ZnO}$ solid surface be:

$$
\begin{gathered}
\mathrm{O}_{2(\mathrm{~g})}+\mathrm{e}^{-} \rightleftarrows \mathrm{O}_{2(\mathrm{ads})}^{-} \\
\mathrm{O}_{2(\mathrm{ads})}^{-}+\mathrm{e}^{-} \rightleftarrows 2 \mathrm{O}^{-}{ }_{\text {(ads) }}
\end{gathered}
$$

If

$$
\Gamma_{\mathrm{O}_{2}^{-}} \ll \Gamma_{\mathrm{O}^{-}}
$$

where $\Gamma$ represents the surface concentrations of adsorbed oxygen species then: 


$$
\frac{\mathrm{d} \Gamma_{\mathrm{O}^{-}}}{\mathrm{dt}}=2 \mathrm{p}_{\mathrm{O}_{2}}\left[\mathrm{e}^{-}\right]^{2}
$$

where $\frac{\mathrm{d} \Gamma_{\mathrm{O}^{-}}}{\mathrm{dt}}$ represent the variation of concentration of oxygen ions, $\mathrm{O}^{-}$, adsorbed on the surface in time, $\mathrm{p}_{\mathrm{O}_{2}}$ - the oxygen partial pressure on the surface of the solid material and $\left[\mathrm{e}^{-}\right]$is the electron concentration. Neglecting an opposite reaction in formula (6), then after Boltzmann:

$$
\mathrm{n}_{\mathrm{e}(\mathrm{x}=0)}=\mathrm{n}_{\mathrm{e}(\mathrm{x}=\infty)} \exp \left[-\frac{\mathrm{eV}_{\mathrm{D}}}{\mathrm{kT}}\right]
$$

with:

$$
\mathrm{V}_{\mathrm{D}}=\varphi_{(\mathrm{x}=\infty)}-\varphi_{(\mathrm{x}=0)}
$$

$\mathrm{V}_{\mathrm{D}}$ - being the diffusion potential; $\mathrm{x}=0$ is on the surface and $\mathrm{x}=\infty$, inside the solid; $\varphi$ - the local electric potential, that can be estimated using a Poisson equation; $\mathrm{n}_{\mathrm{e}(\mathrm{x}=0)}$ is the number of electrons at the surface; $\mathrm{n}_{\mathrm{e}(\mathrm{x}=\infty)}$ - the number of electrons inside the solid; e - elementary charge; $\mathrm{k}$ - Boltzmann constant and $\mathrm{T}$ - the temperature expressed in $\mathrm{K}$. For $\mathrm{ZnO}$ which is an n-type semiconductor, neglecting the cations movement, one obtains:

$$
\frac{\mathrm{d}^{2} \varphi}{\mathrm{dx}^{2}}=-\frac{4 \pi \varphi}{\varepsilon}=-\frac{4 \pi \mathrm{e}}{\varepsilon}\left[\mathrm{n}_{\mathrm{e}(\mathrm{x}=0)}-\mathrm{n}_{\mathrm{e}(\mathrm{x}=\infty)}\right]
$$

$\varepsilon$ being the dielectric constant. But also, after Boltzmann:

$$
\mathrm{n}_{\mathrm{e}}=\mathrm{n}_{\mathrm{e}(\mathrm{x}=0)} \exp \left(\frac{\mathrm{e} \varphi}{\mathrm{kT}}\right)
$$

where $\varphi_{(\mathrm{x}=\infty)}=0$. One obtains now:

$$
\frac{\mathrm{d}^{2} \varphi}{\mathrm{dx}^{2}}=-\frac{4 \pi \mathrm{en}_{\mathrm{e}(\mathrm{x}=\infty)}}{\varepsilon}\left[1-\exp \left(\frac{\mathrm{e} \varphi}{\mathrm{kT}}\right)\right]
$$

or

$$
\frac{1}{2} \mathrm{~d}\left(\frac{\mathrm{d} \varphi}{\mathrm{dx}}\right)^{2}=-\frac{4 \pi \mathrm{en}}{\varepsilon} \mathrm{e}(\mathrm{x}=\infty)_{1}\left[1-\exp \left(\frac{\mathrm{e} \varphi}{\mathrm{kT}}\right)\right] \mathrm{d} \varphi
$$

The integration of equation (14) between: $\varphi(\mathrm{x}=0)=-\mathrm{V}_{\mathrm{D}}, \varphi(\mathrm{x}=\infty)=0$

and $\left(\frac{\mathrm{dq}}{\mathrm{dx}}\right)_{\mathrm{x}=\infty}=0$, leads finally:

Or

$$
0-\frac{1}{2} \mathrm{~d}\left(\frac{\mathrm{d} \varphi}{\mathrm{dx}}\right)_{\mathrm{x}=0}=4 \pi \mathrm{en}_{\mathrm{e}(\mathrm{x}=\infty)}\left\{0-\left(-\mathrm{V}_{\mathrm{D}}\right)-\frac{\mathrm{kT}}{\mathrm{e}}\left[\exp \left(-\frac{\mathrm{eV}_{\mathrm{D}}}{\mathrm{kT}}\right)-1\right]\right\}
$$

$$
\left(\frac{\mathrm{d} \varphi}{\mathrm{dx}}\right)^{2}=\frac{8 \pi \mathrm{en}_{\mathrm{e}(\mathrm{x}=\infty)}}{\varepsilon}\left[\mathrm{V}_{\mathrm{D}}+\frac{\mathrm{kT}}{\mathrm{e}}\left[1-\exp \left(-\frac{\mathrm{eV}}{\mathrm{kT}}\right)\right]\right.
$$

Concerning now only the adsorption of $\mathrm{O}^{-}$ions it results:

$$
\left(\frac{\mathrm{dq}}{\mathrm{dx}}\right)_{\mathrm{x}=0}=\frac{4 \pi \mathrm{e}}{\varepsilon} \Gamma_{\mathrm{O}^{-}}
$$

By using equation (17) in equation (16) the result is:

$$
\frac{16 \pi^{2} \mathrm{e}^{2} \Gamma_{\mathrm{O}^{-}}^{2}}{\varepsilon^{2}}=8 \pi \mathrm{en}_{\mathrm{e}(\mathrm{x}=\infty)}\left\{\mathrm{V}_{\mathrm{D}}+\frac{\mathrm{kT}}{\mathrm{e}}\left[1-\exp \left(-\frac{\mathrm{eV} \mathrm{D}}{\mathrm{kT}}\right)\right]\right\}
$$

In order to simplify the equation, it was assumed that

$$
\frac{\mathrm{eV}_{\mathrm{D}}}{\mathrm{kT}} \gg 1
$$

So, one obtains:

$$
\frac{16 \pi^{2} \mathrm{e}^{2} \Gamma_{\mathrm{O}^{-}}^{2}}{\varepsilon^{2}} \cong 8 \pi \mathrm{en}_{\mathrm{e}(\mathrm{x}=\infty)}\left(\mathrm{V}_{\mathrm{D}}+\frac{\mathrm{kT}}{\mathrm{e}}\right) \approx \frac{8 \pi \mathrm{en}_{\mathrm{e}(\mathrm{x}=\infty)}}{\varepsilon} \mathrm{V}_{\mathrm{D}}
$$


and

$$
\mathrm{V}_{\mathrm{D}}=\frac{2 \pi \mathrm{e} \Gamma_{\mathrm{O}^{-}}^{2}}{\varepsilon \mathrm{n}_{\mathrm{e}(\mathrm{x}=\infty)}}
$$

By introducing equations (9) and (21) in equation (8) it results:

$$
\frac{\mathrm{d} \Gamma_{\mathrm{O}^{-}}}{\mathrm{dt}}=2 \mathrm{kp}_{\mathrm{O}_{2}}\left[\mathrm{n}_{\mathrm{e}(\mathrm{x}=\infty)}\right]^{2} \exp \left[-\frac{4 \pi \mathrm{e}^{2} \Gamma_{\mathrm{O}^{-}}^{2}}{\varepsilon \mathrm{kT} \mathrm{n}_{\mathrm{e}(\mathrm{x}=\infty)}}\right]
$$

or in a shorter form:

$$
\frac{\mathrm{d} \Gamma_{\mathrm{O}^{-}}}{\mathrm{dt}}=\alpha \exp \left(-\beta \Gamma_{\mathrm{O}^{-}}^{2}\right)
$$

which is not a logarithmic equation $(\infty, \beta$ are constants).

In cases of the reactions:

$$
\mathrm{O}_{2(\mathrm{ads})}^{-}=\mathrm{O}_{(\mathrm{ads})}+\mathrm{O}_{(\mathrm{ads})}^{-}
$$

or

$$
\mathrm{O}_{(\text {ads })}+\mathrm{e}^{-}=\mathrm{O}_{(\text {ads })}^{-}
$$

one obtains, using the same form of calculus, the equation:

$$
\frac{\mathrm{d} \Gamma_{\mathrm{O}^{-}}}{\mathrm{dt}}=\alpha \mathrm{p}_{\mathrm{O}_{2}} \mathrm{n}_{\mathrm{e}(\mathrm{x}=\infty)} \exp \left[-\frac{2 \pi \mathrm{e}^{2} \Gamma_{\mathrm{O}^{-}}^{2}}{\varepsilon \mathrm{kTn} \mathrm{n}_{\mathrm{e}(\mathrm{x}=\infty)}}\right]
$$

Equation (26) is also not a logarithmic one.

Perhaps the cases presented in equations (5)-(7) and (24), (25) are not the only cases when the adsorption of oxygen on an n-type semiconductor like $\mathrm{ZnO}$ does not obey a logarithmic rate law.

It should be mentioned that in order to claim the existence or the non existence of a logarithmic kinetics for the oxygen adsorption or desorption processes it is necessary to fit the data over a wide range of experimental values.

Equations (23) and (26) demonstrate that the theory of ionosorption can be successfully used to describe cases in which different forms of adsorbed oxygen are in excess on a surface.
Several possible mechanisms containing relevant elementary steps for the ionosorption of oxygen on an n-type semiconductor can exist and the two cases presented in this paper could be some of them.

\section{CONCLUSIONS}

The kinetics of oxygen adsorption on an n-type semiconductor like $\mathrm{ZnO}$ obeys normally a logarithmic rate law. But in cases when different forms of ionosorbed oxygen are predominant on the surface, the logarithmic rate law kinetics cannot be used.

Acknowledgements. The authors are gratefully acknowledged the support of the EU (ERDF) and Roumanian Government which approved acquisition of the research infrastructure under POS-CCE O 2.2.1 project INFRANANOCHEM - No. 19/01.03.2009.

\section{REFERENCES}

1. C. Aharoni and F. C. Tompkins, Adv. Catalysis, 1970, $20,1$.

2. K. Hauffe and S. R. Morrison, "Adsorption" de Gruyter Verlag, Berlin, 1974, p. 87.

3. P. Fejes, "Contact Catalysis", Z.G. Szabo and D. Kallo (Eds.), Akademiai Kiado, vol.1, Budapest, 1976, p. 223.

4. S. R. Morrison, "The Chemical Physics of Surfaces", Plenum Press, New York and London, 1978, p. 46, 241.

5. E. I. Segal, N. I. Ionescu, D. M. Razus and I. N. Salageanu, "Cinetica reactiilor catalitice eterogene", vol. I, Ed. Academiei Române, 1992, p. 87.

6. E. I. Segal, C. Iditoiu, N. Doca and D. Fatu, "Cataliza si catalizatori”, Ed. Facla, Timişoara, 1986, p. 40.

7. S. Morrison, Sens. Actuators, 1987, 11, 283.

8. N. I. Ionescu, Surf. Sci., 1976, 61, 294.

9. N. I. Ionescu, Z. Phys. Chemie- Neue Folge, 1978, 109, 95.

10. N. I. Ionescu, Bulg. Chem. Commun., 1992, 25, 39.

11. N. I.Ionescu and M. Caldararu, Rev. Roum. Chim., 2002, 47, 1213.

12. N. I.Ionescu and M. Caldararu, Rev. Roum. Chim., 2006, 51,521 .

13. N. I. Ionescu and M. Caldararu, Rev. Roum. Chim., 2008, 53,603 .

14. J. F. Wager, Thin Solid Films, 2008, 516, 1755.

15. N. I. Ionescu, Rev. Roum. Chim., 2008, 53, 603.

16. N. I. Ionescu and M. Caldararu, Rev. Roum. Chim., 2010, 55,365 .

17. N. I. Ionescu, Rev. Roum. Chim., 2011, 56, 483. 
